\title{
Implementasi Service Learning Terhadap Kemampuan Membaca dan Menulis Permulaan Siswa SD/MI
}

\section{Andi Halimah'*, Suharti2, Nur Akni Ardita ${ }^{3}$}

\footnotetext{
1,2,3 Jurusan Pendidikan Matematika, UIN Alauddin Makassar, Gowa, Indonesia
}

\section{ART ICLE INF O}

Article history:

Received May 09, 2021

Revised May 15, 2021

Accepted June 20, 2021

Available online July 25, 2021

\section{Kata Kunci:}

Membaca, Menulis, Permulaan, Service Learning

Keywords:

Reading, Writing, Beginning,

Service Learning

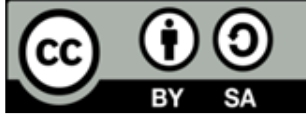

This is an open access article under the CC BY-SA license.

Copyright $(2021$ by Author. Published by Universitas Pendidikan Ganesha.

\begin{abstract}
A B S T R A K
Masih banyak siswa yang mengalami kesulitan dalam membaca dan menulis. Selain itu, guru kewalahan dalam membelajarkan siswa yang belum mampu membaca dan menulis dengan baik. Penelitian ini bertujuan untuk menganalisis pengaruh implementasi kegiatan service learning mahasiswa prodi PGMI terhadap kemampuan membaca dan menulis permulaan siswa SD/MI. Jenis penelitian ini adalah eksperimen dengan desain pre-eksperimental design. Jumlah mahasiswa yang melakukan kegiatan service learning sebanyak 79 orang sehingga sampelnya berjumlah 79 orang. Instrumen yang digunakan untuk memperoleh data dalam penelitian adalah tes, yakni pretes dan posttes. Teknik analisis data berupa analisis deskriptif maupun inferensial. Hasil penelitian menunjukkan bahwa ada pengaruh implementasi kegiatan service learning terhadap kemampuan membaca dan menulis permulaan siswa SD/MI yang dilakukan oleh Mahasiswa. Setiap masalah yang dihadapi siswa diberi solusi oleh mahasiswa dengan menggunakan metode, eja, metode suku kata, metode global, dan metode SAS. Implikasi dari penelitian ini adalah mendekatkan mahasiswa pada masalah yang terjadi di masyarakat dan memberikan bantuan terhadap kesulitan belajar di sekolah, hal tersebut sebagai praktik pembelajaran mata kuliah Bahasa Indonesia di bangku kuliah dengan langsung mendampingi dalam mengatasi masalah pembelajaran.
\end{abstract}

\section{A B S T R A C T}

There are still many students who have difficulty in reading and writing. In addition, teachers are overwhelmed in teaching students who have not read and write well. This study aims to analyze the effect of implementing service-learning activities for students of the PGMI study program on the early reading and writing skills of elementary/MI students. This type of research is an experimental design with a preexperimental design. The number of students who carried out service-learning activities was 79 people so that the sample was 79 people. The instrument used to obtain data in the study was a test, namely pretest and posttest-data analysis techniques in the form of descriptive and inferential analysis. The study results indicate that there is an effect of implementing service-learning activities on the students' initial reading and writing skills of SD/MI students. Every problem students face is given a solution by using the method, spelling, syllable method, global method, and SAS method. The implication of this research is to bring students closer to problems in the community and provide assistance to learning difficulties at school; this is a practice of learning Indonesian language courses in college by directly assisting in overcoming learning problems.

\section{PENDAHULUAN}

Belajar membaca bisa mendukung seseorang dalam menuntut ilmu, mendapat informasi, menambah perbendaharaan kata, istilah, serta ungkapan (Cahyaningsih, 2019; Yunita et al., 2017). Dalam belajar membaca siswa akan diperkenalkan dengan membaca permulaan. Membaca permulaan ialah keterampilan paling awal yang wajib dikuasi oleh siswa (Deja et al., 2021; Le et al., 2019; Szanto, 2020). Proses membaca permulaan memuat perkenalan huruf, beberapa unsur ilmu bahasa, hubungan pola dalam ejaan, serta kecepatan dalam membaca (Hermansyah et al., 2019; Sabrina \& Laily, 2016). Keterampilan membaca permulaan cenderungnya diarahkan untuk kemampuan membaca terdasar yakni pengetahuan akan huruf-huruf (Chandra \& Amerta, 2017). Selain kemampuan membaca siswa juga dituntut untuk memiliki kemampuan menulis. Menulis ialah 
suatu kepiawaian yang padat dan juga melibatkan kemampuan kebahasaan (Aprelia et al., 2019; Pradnyawathi et al., 2019). Menulis juga termasuk suatu kebiasaan dan atau membutuhkan pembiasaan, semakin sering menulis maka orang tersebut juga semakin mahir menulis (Masrur et al., 2020; Szanto, 2020). Menulis pada jenjang SD di kelas awal diistilahkan menulis permulaan. Kepiawaian menulis permulaan dikatakan sebagai kemampuan yang dipusatkan dalam kemampuan yang sifatnya mekanik, yakni teknik dalam memanfaatkan fungsi dari alat tulis agar membentuk sebuah tulisan yang bisa dibaca (Pradnyawathi et al., 2019; Yusnidar, 2014). Saat belajar menulis sebaiknya kondisi pembelajaran pemelajar divisualisasikan dengan huruf yang benar, diarahkan, diarahkan untuk bisa mendengarkan dengan seksama, serta melafalkan huruf dengan jelas (Nuzulia, 2016; Widayanti et al., 2019).

Permasalahan yang terjadi saat ini yaitu masih banyak siswa yang mengalami kesulitan dalam membaca dan menulis (Astuti \& Istiarini, 2020; Azmussya'ni \& Wangid, 2014; Warsihna, 2016). Dari informasi awal yang didapat dari para guru di SD dan MI yang berada di sekitar tempat domisili mahasiswa, mayoritas siswa masih sulit untuk membaca juga menulis. Terutama di awal masuk sekolah, banyak guru yang kewalahan dalam membelajarkan siswanya. Hal ini disebabkan keterlambatan dalam membaca dan menulis. Kesulitan siswa saat kelas awal adalah mengenal huruf dan merangkainya menjadi suku kata dan kata. Demikian pula menulis, siswa kadang terhambat untuk membedakan huruf tertentu misalnya: "b, d, p, q", dan beberapa huruf yang memiliki kemiripan. Kesulitan mereka belajar membaca dan menulis di awal masuk sekolah banyak dialami oleh siswa dan hal ini menjadi kendala guru dalam membelajarkan siswanya. Penelitian sebelumnya juga menyatakan bahwa guru yang mengajar di kelas awal banyak yang kesulitan membelajarkan siswanya membaca dan menulis (Muhammad et al., 2019; Ni'matuzahroh, 2015). Kesulitan menandai bunyi huruf, membedakan antara bentuk huruf kapital dengan huruf kecil yang mirip, merangkai padanan kata, membalik huruf, menghilangan huruf dalam sebuah kata, mengeja yang masih terbata-bata, serta sulitnya konsentrasi pembelajar menjadi penghembat mereka dalam membaca permulaan (Hermansyah et al., 2019; Windrawati et al., 2020). Faktor yang menjadi hambatan membaca pemelajar di kelas satu lazimnya karena prasyarat membaca yang belum memenuhi (Capellini et al., 2015). Penghambat pemelajar dalam membaca permulaan memuat factor: lingkungan, psikologis, dan intelektual (Pramesti, 2018). Permasalahan dalam menulis yang sering didapati pemelajar ialah dalam penulisan ejaan, belum mengetahui tanda baca, dan kurangnya kerapihan saat menulis (Azmussya'ni \& Wangid, 2014; Rojaki, 2012). Keinginan menulis pemelajar yang kurang juga menjadi salah satu penghambat (Fuad \& Helminsyah, 2018; Sismulyasih, 2015). Siswa yang ada pada situasi tertekan akan condong apatis pada kegiatan menulis sehingga tidak bisa menulis dengan baik (Ahsin, 2016).

Hal ini menyebabkan pembelajaran membutuhkan strategi tersendiri bagi guru. Banyak keluhan guru terkait kesulitan membelajarkan peserta didiknya membaca dan menulis di awal siswa masuk jenjang sekolah dasar sebab ada yang sudah mampu membaca-menulis dan juga ada yang belum (Pramesti, 2018; Yunita et al., 2017). Siswa yang mengalami kesulitan belajar baik membaca ataupun menulis, diberikan layanan jasa (service learning) berupa pendampingan sebagai implementasi dari ilmu yang diperoleh pada mata kuliah Pembelajaran Bahasa Indonesia. Service learning merupakan metode pembelajaran yang dalam pelaksanaannya mengintegrasikan pembelajaran dengan pelayanan kepada masyarakat (Chiva-Bartoll et al., 2021; Spencer, 2021). Service learning adalah strategi yang mengintegrasikan pendidikan dengan akademik untuk peningkatan pengetahuan (Alexander-Ruff \& Ruff, 2021; Kovalenko \& Vellenga, 2021). Selain hal tersebut diharapkan juga dapat membangun kesadaran peserta didik pada lingkungan dan masyarakat. Ilmu yang diperoleh di bangku kuliah dimanfaatkan untuk membantu masyarakat yang membutuhkan jasa layanan. Dalam pelaksanaan kegiatan service learning, antara dosen dan mahasiswa harus terjadi komunikasi yang efektif (Syamsudduha \& Tekeng, 2017). Khususnya dalam dunia pendidikan, kegiatan service learning dilakukan dengan memberikan jasa layanan pada individu sekitar yang mempunyai anak dengan usia tingkat sekolah dasar atau madrasah ibtidaiyah yang mengalami kesulitan dalam belajar bahasa Indonesia khususnya membaca atau menulis. Service learning menyajikan penerapam praktis dibanding ilmu baru serta beberapa keterampilan dari tugas dan kegiatan lain (García-Rico et al., 2021; Rodríguez-Izquierdo, 2021). Manfaat dari service learning ialah mengarahkan potensi akademik, sikap, serta psikomotorik pebelajar jadi lebih baik (Saito et al., 2021). Dari uraian tersebut service learning tidak hanya meningkatkan pencapaian pembelajaran peserta didik tetapi meningkatkan keterampilan dan sikap. Hal ini yang mendasari penelitian ini yang bertujuan untuk mendeskripsikan pengaruh implementasi kegiatan service learning mahasiswa prodi PGMI terhadap kemampuan membaca dan menulis permulaan siswa SD/MI.

Temuan penelitian sebelumnya juga menyatakan bahwa service learning akan memudahkan siswa dalam belajar (Márquez-García et al., 2020; Suryandari et al., 2018). Penelitian lainnya juga menyatakan bahwa service learning efektif diterapkan dalam membantu siswa belajar (Armstrong et al., 2021; Fakhruddin et al., 2019). Target dan sasaran kegiatan service-learning yang akan diberikan layanan dari para mahasiswa PGMI UIN Alauddin Makassar adalah siswa terutama yang berada di kelas awal yakni kelas 1 sampai kelas 3 SD/MI yang memiliki kesulitan dalam membaca dan menulis. Setiap mahasiswa ditugasi untuk mengidentifikasi para siswa yang sulit membaca maupun menulis di SD/MI yang ada sekitar tempat domisili mahasiswa dan berdasarkan rekomendasi guru. Mahasiswa memilih satu siswa yang akan diberikan pendampingan berupa layanan 
pembelajaran membaca atau menulis sesuai kebutuhannya. Hal ini dimaksudkan agar mahasiswa yang sudah belajar teori pembelajaran bisa mengaplikasikan ilmunya secara langsung, karena mereka memerlukan pengalaman yang dapat membuat dirinya merasa bertanggung jawab pada masyarakat, lingkungan, dan Pendidikan. Tujuan penelitian in yaitu untuk menganalisis pengaruh implementasi kegiatan service learning mahasiswa terhadap kemampuan membaca dan menulis permulaan siswa SD/MI. diharapkan penerapan kegiatan service learning dapat membantu meningkatkan kemampuan membaca dan menulis permulaan pada siswa sekolah dasar.

\section{METODE}

Jenis penelitian ini yaitu pre-eksperimental yakni dengan mengikutsertakan suatu kelompok subyek, dengan demikian tidak terdapat pengontrolan ketat pada variable ekstra (Mustami, 2015). Desain penelitian ini ialah one group pretes-postes. Lokasi penyelenggaraan penelitian di Prodi PGMI Fakultas Tarbiyah dan Keguruan dan pendampingannya di wilayah domisili masing-masing mahasiswa. Adapun populasi untuk penelitian ini ialah mahasiswa dari Prodi PGMI UIN Alauddin Makassar semester IV yang belajar mata kuliah Pembelajaran Bahasa Indonesia berjumlah 79 orang mahasiswa. Pilihan sampel untuk penelitian ini mengacu dari purposive sampling. Dari pertimbangan pemilihan sampel yaitu jumlah mahasiswa yang melakukan kegiatan service learning sebanyak 79 sehingga sampelnya berjumlah 79 orang yang mendampingi 79 siswa yang kesulitan untuk membaca-menulis didasari arahan guru SD/MI di tempat domisili mahasiswa. Alat ukur (instrumen) untuk mendapatkan data ialah tes, yakni pretes dan posttes yang diberikan kepada siswa terdamping untuk mengukur dampak atau pengaruh implementasi kegiatan service learning dan untuk mengetahui ketercapaian tujuan pembelajaran bagi mahasiswa dan siswa terdamping. Instrumen pengumpulan data yang digunakan adalah soal membaca-menulis kata hingga kalimat yang sederhana menggunakan metode: eja, suku kata, SAS, global, dan abjad/ bunyi. Kata dan kalimat sederhana yang disiapkan untuk dibaca dan ditulis adalah konteks kata dan kalimat yang sehari-hari sering didengar dan diucapkan oleh siswa. Indikator membaca dan menulis permulaan diklasikasikan dengan kategori yag ditunjukkan pada tabel 1.

Tabel 1. Indikator membaca dan menulis

\begin{tabular}{ll}
\hline \multicolumn{1}{c}{ Klasifikasi } & \multicolumn{1}{c}{ Keterangan } \\
\hline Membaca Lancar (BL) & Jika kemampuan membaca siswa telah mampu mengeja huruf dengan \\
& jelas dan mampu membaca kata dan kalimat sederhana dengan baik \\
Membaca Kurang (BK) & $\begin{array}{l}\text { Jika kemampuan membaca siswa tidak mampu atau sedikit mampu } \\
\text { mengeja huruf tidak lancar dan salah menyebutkan kata }\end{array}$ \\
Menulis Baik (TB) & Jika kemampuan menulis siswa telah mampu menulis huruf dan kata \\
& dengan baik. \\
Menulis Kurang (TK) & Jika kemampuan siswa baik dan tulisan kata tidak jelas \\
\hline
\end{tabular}

Adapun metode untuk mendapatkan data yang dipergunakan ialah tes kemampuan membaca dan menulis dilakukan dengan memberi tes awal sebelum pendampingan dan tes akhir setelah pendampingan untuk melihat pengaruh implementasi kegiatan service learning bagi siswa SD/MI. Observasi yang dimaksudkan ialah observasi pada partisipan yakni mahasiswa memberikan pelayanan jasa terhadap siswa yang berkesulitan membaca dan menulis. Siswa didentifikasi kendala awalnya (tes awal), kemudian diberikan layanan sesuai kebutuhannnya sambil diamati setiap tahapan perkembangan yang menunjukkan peningkatan kemampuan dalam membaca dan menulis. Data didapatkan melalui analisis deskriptif dalam memperoleh gambaran hasil dari pemberian tes membaca dan menulis permulaan kepada siswa dan analisis inferensial untuk memperoleh data terkait pengaruh implementasi servis learning KMMP siswa SD/MI.

\section{HASIL DAN PEMBAHASAN}

Hasil

Dari analisis deskriptif, data yang diolah pada saat sebelum diaplikasikan kegiatan service learning matakuliah Pembelajaran Bahasa Indonesia diperoleh gambaran tentang skor KMMP siswa SD/MI ditampilkan pada Gambar 1. Hasil analisis menunjukkan bahwa tidak terdapat siswa dengan kemampuan membaca lancar atau bisa disebut besarannya $0 \%$, dan seluruh siswa dengan kemampuan membaca kurang sebesar $100 \%$ sementara dari analisis pretest tidak terdapat siswa dengan kemampuan menulis baik (0\%) dan seluruh siswa dengan kemampuan menulis kurang sebesar 100\% sebelum diterapkan kegiatan service learning pada Pembelajaran Bahasa Indonesia. Untuk hasil penelitian setelah dilaksankan pembelajaran service learning diperoleh hasil sudah tidak terdapat siswa dengan kemampuan membaca kurang atau dengan besarannya $0 \%$, dan seluruh siswa justru berubah menjadi kemampuan membaca lancar sebesar $100 \%$. Sementara hasil analisis 
menulis permulaan saat posttest adalah $0 \%$ atau tidak ada lagi siswa dengan menulis kurang dan $100 \%$ atau seluruh siswa berkemampuan menulis baik. Dalam penelitian ini tidak dilakukan pengujian prasyarat penelitian dalam bentuk uji normalitas data dan homogenitas data, hal ini di karenakan pada penelitian ini data terkait kemampuan membaca dan menulis dianalisis berdasarkan kategori (nominal) sehingga data akan akan langsung dianalisis menggunakan analisis nonparametrik menggunakan uji mean windows SPSS 2.1. Analisis terkait pengaruh implementasi kegiatan service learning matakuliah Pembelajaran Bahasa Indonesia terhadap KMMP pebelajar SD/MI oleh mahasiswa PGMI. Pengujian perbedaan ini bertujuan untuk menetapkan ada tidaknya perbedaan pengaruh yang signifikan implementasi kegiatan service learning matakuliah Pembelajaran Bahasa Indonesia uji nonparametrik menggunakan windows SPSS 2.1 hasil yang didapatkan yaitu 5,991. Nilai $X_{0}^{2}=13$, $067>X_{0,05}^{2}(2)=5,991$ maka $\mathrm{H}_{1}$ diterima. Jika dibandingkan hasil pretest dan posttest, maka terlihat jelas bahwa terjadi perubahan yang baik setelah service learning diaplikasikan. Kemampuan membaca siswa yang awalnya keseluruhan disebut membaca kurang (BK) justru keseluruhan beralih menjadi membaca lancar (BL). Begitu juga dengan kemampuan menulis, yang awalnya keseluruhan dikatakan menulis kurang (TK) justru berubah pula keseluruhan menjadi menulis lancar (TL). Dengan demikian, dapat dikatakan ada pengaruh implementasi kegiatan service learning terhadap KMMP pebelajar SD/MI.

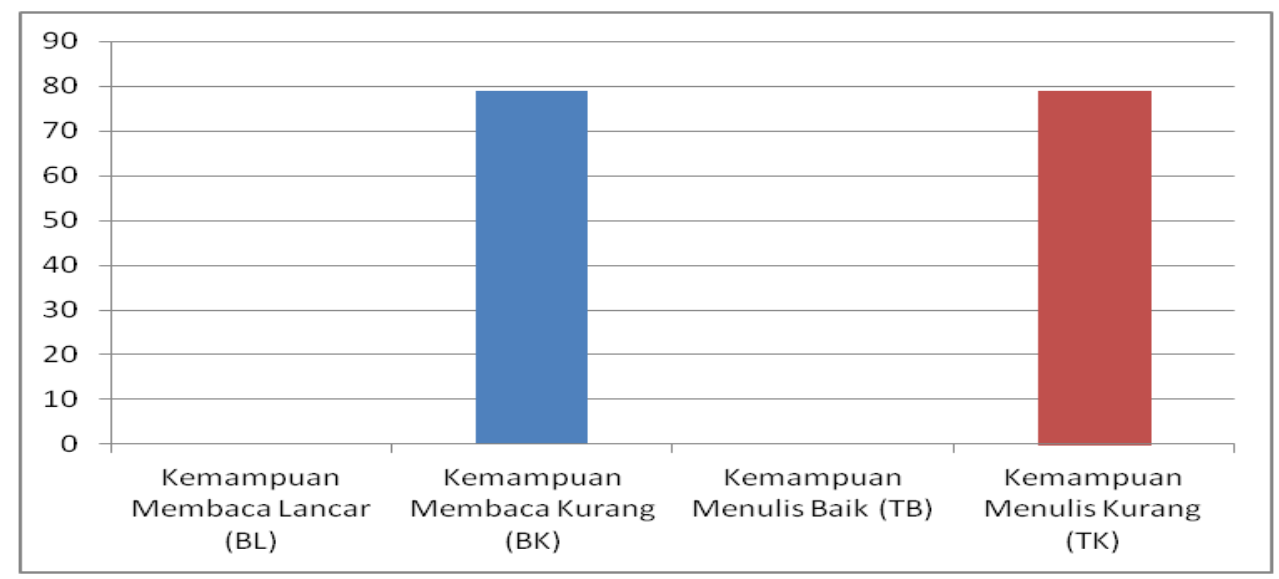

Gambar 1. Kemampuan membaca dan menulis sebelum diterapkan kegiatan service learning

Hasil penelitian menunjukkan bahwa ada pengaruh implementasi kegiatan service learning terhadap kemampuan membaca dan menulis permulaan. Hal ini disebabkan oleh beberapa factor yaitu sebagai berikut. Pertama, implementasi kegiatan service learning dapat memudahkan siswa dalam belajar. Pencapaian hasil yang diperoleh siswa tersebut, tidak lepas dari peran mahasiswa dalam melakukan pendampingan kegiatan service learning secara terstruktur dan terencana sesuai dengan kebutuhan siswa terdamping dengan menerapkan teori service learning dan metode Membaca-Menulis Permulaan dengan perpaduan metode: eja, global, kata, dan SAS. Pendampingan ini memudahkan siswa dalam belajar (Widiarti, 2017; Yasin et al., 2019; Yulianingsih et al., 2020). Tahapan pendampingan dilakukan dengan melakukan identifikasi awal kemampaun menulis dan membaca awal peserta didik SD/MI yang akan didampingi. Setelah mengetahui masalahnya, mahasiwa mengatur rencana metode yang akan digunakan untuk melakukan pendampingan. Perencanaan strategi ini penting agar kegiatan pembelajaran berjalan dengan lancar, pendidik juga tidak kelabakan saat menghadapi pebelajar (Bera \& Lukas, 2018; Li et al., 2021; Rosciano, 2015). Masing-masing dengan strateginya mencoba secara bertahap sesuai kebutuhan siswa dampingannya. Yang belum mengenal huruf, didampingi untuk mempelajari huruf, menyusun huruf menjadi suku kataa, membaca kata, sampai mampu membaca kalimat sederhana. Demikian pula yang belum tahu menulis dan membedakan huruf terus dilatih dengan menggunakan metode menulis dan membaca awal sesuai teori yang telah diperoleh di bangku kuliah. Hasilnya secara bertahap siswa dampingan mengalami kemajuan yang berarti. Hal ini menegaskan bahwa service learning memudahkan siswa dalam belajar (Saprudin et al., 2020; Syamsudduha \& Tekeng, 2017).

Kedua, implementasi kegiatan service learning dapat memberikan pengalaman belajar kepada mahasiswa dan siswa yang didampingi. Pengalaman mahasiswa mendampingi siswa dalam kegiatan service learning menjadi pengetahuan yang berarti bagi pemahaman teori yang telah dipelajari (Alexander-Ruff \& Ruff, 2021; Bhattacharjee \& Deb, 2016). Saat implementasi kegiatan service learning ini, mahasiswa mendapat pengalaman berharga ketika membelajarkan siswa yang tidak mampu membaca dan menulis, lalu mengalami 
kemajuan sangat pesat menjadi mampu membaca dan menulis berkat dampingan mahasiswa. Mahasiswa memiliki kesmpatan berinteraksi langsung dengan situasi yang kontekstual dan memberi solusi bagi siswa yang mengalami kesulitan (Kovalenko \& Vellenga, 2021; Spencer, 2021). Service learning sangat bermanfaat dan memberikan pengalaman bagi mahasiswa dan solusi bagi siswa yang terdampingi (Mustofa, 2019). Dengan demikian, implementasi kegiatan service learning bisa menjadi salah satu solusi dalam meningkatkan ketuntasan pembelajaran bagi mahasiswa dan siswa. Untuk peneliti selanjutnya dapat menyandingkan antara service learning dengan penggunaan model-model pembelajaran berdasarkan karakter pebelajar SD/MI dan disertai metode games.

Temuan penelitian lainnya juga menyatakan bahwa service learning akan memudahkan siswa dalam belajar (Márquez-García et al., 2020; Suryandari et al., 2018). Temuan penelitian sebelumnya juga menyatakan bahwa service learning memberikan dampak bagi siswa dalam segi peningkatan pengetahuan (Saprudin et al., 2019; Syamsudduha \& Tekeng, 2017). Tujuan model pembelajaran service learning ini selain mengajarkan mahasiswa tentang pengetahuan dalam situasi nyata pada masyarakat dan mampu dalam mengatasinya, dan dapat membentuk karakter agar mereka mempunyai kesadaran peduli pada kaum yang lemah dan tersisihkan (Karlela \& Anisah, 2016; Syamsudduha \& Tekeng, 2017). Service learning menjadi jembatan penghubung pembelajaran dan pelayanan melalui sebuah refleksi. Selain dapat mengembangkan dimensi spiritual dan sosial, juga menjembatani kesenjangan teori yang dipelajari di kelas dan praktik nyata dalam kehidupan masyarakat (Soegondo \& Arifin, 2020). Service learning membantu mahasiswa dalam mengasah kemampuan kritis dalam berbagai situasi dan kondisi sosial yang ia hadapi dalam masyarakat. Mahasiswa diberikan motivasi agar terlatih dalam mencapai kematangan intelektual dengan menghadapi persoalan nyata (Rahzianta \& Hidayat, 2016). Implikasi penelitian ini yaitu penerapan service learning kepada siswa dapat meningkatkan kemampuan siswa dalam membaca dan menulis.

\section{SIMPULAN}

Terdapat pengaruh implementasi kegiatan service learning pada KMMP pebelajar SD/MI. Hal ini disebabkan pendampingan yang dilakukan oleh mahasiswa telah berlangsung dengan baik. Setiap masalah yang dihadapi siswa diberi solusi oleh mahasiswa dengan menggunakan metode, eja, metode suku kata, metode global, dan metode SAS. Siswa mendapatkan ilmu dan pengalaman yang bermanfaat bagi diri dan lingkungannya. Direkomendasikan untuk menerapkan kegiatan service learning sehingga akan membantu siswa yang mengalami kesulitan dalam belajar.

\section{DAFTAR PUSTAKA}

Ahsin, M. N. (2016). Peningkatan Keterampilan Menulis Karangan Narasi Dengan Menggunakan Media Audiovisual Dan Metode Quantum Learning. Jurnal Ilmiah Pendidikan, 6(2), $158-171$. https://doi.org/https://doi.org/10.24176/re.v6i2.607.

Alexander-Ruff, J. H., \& Ruff, W. G. (2021). The impact of cultural immersion service learning on BSN graduates: A quasi-experimental evaluation. Nurse Education in Practice, 54. https://doi.org/https://doi.org/10.1016/j.nepr.2021.103099.

Aprelia, D. A., Baedowi, S., \& Mudzantun, M. (2019). Pengaruh Pendekatan Kontekstual Dalam Meningkatkan Keterampilan Menulis Narasi. Mimbar PGSD Undiksha, 7(3), 237-244. https://doi.org/http://dx.doi.org/10.23887/jjpgsd.v7i3.19400.

Armstrong, A. G., Mattson, C. A., \& Lewis, R. S. (2021). Factors leading to sustainable social impact on the affected communities of engineering service learning projects. Development Engineering, 6. https://doi.org/https://doi.org/10.1016/j.deveng.2021.100066.

Astuti, R. F., \& Istiarini, R. (2020). Upaya Meningkatkan Kemampuan Membaca Permulaan AnakUsia 5-6 Tahun Melalui Media Puzzle di PAUD Flamboyan Sukasari Kota Tangerang. Ceria: Jurnal Program Studi Pendidikan Anak Usia Dini, 8(2). https://doi.org/http://dx.doi.org/10.31000/ceria.v11i2.2338.

Azmussya'ni, \& Wangid, M. N. (2014). Peningkatan Keterampilan Menulis Menggunakan Pendekatan Proses Dengan Media Gambar Di Sdn 3 Sakra. Jurnal Prima Edukasia, 2(1), 1-13. https://doi.org/https://doi.org/10.21831/jpe.v2i1.2640.

Bera, \& Lukas. (2018). Peningkatan Partisipasi Belajar Mata Pelajaran IPS Melalui Strategi Pembelajaran Word Square pada Siswa Kelas VA SD Inpres Iligetang. Jurnal Kependidikan, 4(2), 163 - 172. https://doi.org/https://doi.org/10.33394/jk.v4i2.1125.

Bhattacharjee, B., \& Deb, K. (2016). Role of ICT in 21 st Century's Teacher Education. International Journal of Education and Information Studies, 6(1), 1-6.

Cahyaningsih, U. (2019). Penerapan Model Pembelajaran Kooperatif Tipe TAI (Team Assisted Individualization) untuk Meningkatkan Hasil Belajar Siswa pada Mata Pelajaran Matematika. Jurnal Cakrawala Pendas, 5(1), 45-52. https://doi.org/http://dx.doi.org/10.31949/jcp.v4i1.707. 
Capellini, S. A., César, A. B. P. D. C., \& Germano, G. D. (2015). Early identification of reading problems: Preliminary study with students of 1st grade. Procedia - Social and Behavioral Sciences, 174, 1351-1355. https://doi.org/https://doi.org/10.1016/j.sbspro.2015.01.758.

Chandra, \& Amerta, S. (2017). Perwujudan Berpikir Kritis Siswa dalam Implementasi Literasi Membaca Berbasis Strategi The Big Questions and Bookmark Organizers di Sekoah Dasar. Prosiding Seminar Nasional Pendidikan Guru Sekolah Dasar.

Chiva-Bartoll, O., Ruiz-Montero, P. J., Olivencia, J. J. L., \& Grönlund, H. (2021). The effects of service-learning on physical education teacher education: A case study on the border between Africa and Europe. SAGE Journals. https://doi.org/https://doi.org/10.1177/1356336X211007156.

Deja, M., Rak, D., \& Bell, B. (2021). Digital transformation readiness: perspectives on academia and library outcomes in information literacy. The Journal of Academic Librarianship, 47(5). https://doi.org/https://doi.org/10.1016/j.acalib.2021.102403.

Fakhruddin, Z., Amzah, A., \& Nurchalis, N. F. (2019). Technology-Based Teaching Material Development Training for Pre-Service Teachers to Improve Students' Learning Outcomes. NOBEL: Journal of Literature and Language Teaching, 10(1), 87-102. https://doi.org/10.15642/nobel.2019.10.1.87-102.

Fuad, Z. Al, \& Helminsyah. (2018). Language Experience Approach Sebuah Pendekatan Dalam Meningkatkan Keterampilan Menulis Siswa Sekolah Dasar. Jurnal Tunas Bangsa, 5(2), $164-174$. https://doi.org/https://doi.org/10.46244/tunasbangsa.v8i1.

García-Rico, L., Santos-Pastor, M. L., Martínez-Muñoz, L. F., \& Ruiz-Montero, P. J. (2021). The building up of professional aptitudes through university service-learning's methodology in sciences of physical activity and sports. Teaching and Teacher 105. https://doi.org/https://doi.org/10.1016/j.tate.2021.103402.

Hermansyah, A. K., Tembang, Y., \& Purwanty, R. (2019). Penggunaan Media Kartu Warna Kata untuk Meningkatkan Kemampuan Membaca Permulaan Siswa Kelas I SD Inpres Gudang Arang Merauke.

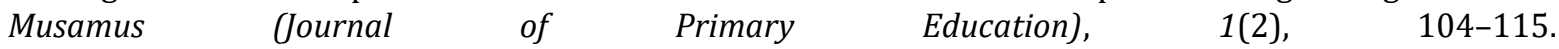
https://doi.org/https://doi.org/10.35724/musjpe.v1i2.1468.

Karlela, D., \& Anisah, A. S. (2016). Penerapan Model Service Learning Untuk Meningkatkan Sikap Kepedulian Sosial Siswa Pada Pembelajaran IPS SD. Jurnal Naturalistic, 1(1), 7-18. https://garuda.ristekbrin.go.id/documents/detail/494870.

Kovalenko, C., \& Vellenga, B. (2021). A Descriptive Analysis of the Experiences of Nursing Students Who Participated in an International Service-Learning Project in Haiti. Journal of Professional Nursing, 6. https://doi.org/https://doi.org/10.1016/j.profnurs.2021.08.003.

Le, T. T. H., Tran, T., Trinh, T. P. T., Nguyen, C. T., Nguyen, T. P. T., Vuong, T. T., Vu, T. H., Bui, D. Q., Vuong, H. M., Hoang, P. H., Nguyen, M. H., Ho, M. T., \& Vuong, Q. H. (2019). Reading habits, socioeconomic conditions, occupational aspiration and academic achievement in Vietnamese junior high school students. Sustainability (Switzerland), 11(18), 1-29. https://doi.org/10.3390/su11185113.

Li, F.-Y., Hwang, G.-J., Chen, P.-Y., \& Lin, Y.-J. (2021). Effects of a concept mapping-based two-tier test strategy on students' digital game-based learning performances and behavioral patterns. Computers \& Education, 24. https://doi.org/https://doi.org/10.1016/j.compedu.2021.104293.

Márquez-García, M. J., Kirsch, W., \& Leite-Mendez, A. (2020). Learning and collaboration in pre-service teacher education: Narrative analysis in a service learning experience at Andalusian public schools. Teaching and Teacher Education, 96. https://doi.org/https://doi.org/10.1016/j.tate.2020.103187.

Masrur, I., Irawati, E., \& Sulistyo, G. H. (2020). Integrating Writing Process with Quantum Learning Framework in English Language Teaching. Jurnal Pendidikan: Teori, Penelitian, Dan Pengembangan, 5(3). https://doi.org/https://doi.org/10.17977/jptpp.v5i3.13262.

Muhammad, Sholichah, \& Aziz. (2019). Pengaruh Budaya Membaca Terhadap Kemampuan Berpikir Kritis Siswa Di SMP Islam Al Syukro Universal Ciputat Tahun 2019. Anragogi, 1(2), 332-343. https://doi.org/http://doi.org/10.36671/andragogi.v1i2.61.

Mustami, K. (2015). Metodologi Penelitian Pendidikan. Yogyakarta: Aynat Publishing.

Mustofa, I. (2019). Praktik Service Learning Manajemen Madrasah Diniah Sebagai Laboratorium Sosial. Intizam: Jurnal Manajemen Pendidikan Islam, 3(1), 14-32.

Ni'matuzahroh. (2015). Efektifitas Strategi Membaca Kolaboratif untuk Meningkatan Pemahaman Bacaan Siswa Sekolah Dasar. Jurnal RAP, 6(2). https://doi.org/https://doi.org/10.24036/rapun.v6i2.6621.

Nuzulia, D. (2016). Pengaruh Penggunaan Media Diorama Papercraft Terhadap Kemampuan Menulis Cerpen Siswa Kelas X Sma Negeri 10 Palembang. Jurnal Ilmu Kependidikan, 4(1). https://doi.org/http://dx.doi.org/10.31851/wahanadidaktika.v14i1.564.

Pradnyawathi, N. N., Chintya, Ngr, G., \& Agustika, S. (2019). Pengaruh Model Pakem Berbasis Tri Hita Karana terhadap Keterampilan Menulis. International Journal of Elementy Education, 3(1), 89-98. https://doi.org/http://dx.doi.org/10.23887/ijee.v3i1.17660.

Pramesti, F. (2018). Analisis Faktor-Faktor Penghambat Membaca Permulaan pada Siswa Kelas 1 SD. Jurnal 
Ilmiah Sekolah Dasar, 2(3), 283-289. https://doi.org/http://dx.doi.org/10.23887/jisd.v2i3.16144.

Rahzianta, \& Hidayat, M. L. (2016). Pembelajaran Sains Model Service Learning Sebagai Upaya Pembentukan Habits Of Mind Dan Penguasaan Keterampilan Berpikir Inventif. Unnes Sciense Education Jurnal, 5(1), 1128-1137. https://doi.org/https://doi.org/10.15294/usej.v5i1.9646.

Rodríguez-Izquierdo, R. M. (2021). Does service learning affect the development of intercultural sensitivity? A study comparing students' progress in two different methodologies. International Journal of Intercultural Relations, 82. https://doi.org/https://doi.org/10.1016/j.ijintrel.2021.03.005.

Rojaki. (2012). Upaya Meningkatkan Kemampuan Menulis Puisi Melalui Model Pembelajaran Sinektik Siswa Kelas X 3 Sma Negeri 2 Sekayu Musi Banyuasin, Sumatera Selatan. Jurnal Ilmiah Guru, 2, 59-72. https://journal.uny.ac.id/index.php/cope/article/view/3964.

Rosciano, A. (2015). The effectiveness of mind mapping as an active learning strategy among associate degree nursing students. Teaching and Learning in Nursing, 10(2). https://doi.org/https://doi.org/10.1016/j.teln.2015.01.003.

Sabrina, A., \& Laily, I. F. (2016). Perbandingan Kemampuan Membaca Permulaan Antara Siswa Kelas I Melalui Tk Dengan Tidak Melalui Tk di Mi PGM Kota Cirebon. Al-Ibtida: Jurnal Pendidikan Guru MI, 3(2), 291-304. https://doi.org/http://dx.doi.org/10.24235/al.ibtida.snj.v3i2.896.

Saito, E., Reisch, R., \& Davis-Risen, S. (2021). Utilizing a faculty-led student assessment team to evaluate international interprofessional service learning opportunities. Currents in Pharmacy Teaching and Learning, 13(9). https://doi.org/https://doi.org/10.1016/j.cptl.2021.06.037.

Saprudin, S., Liliasari, L., Prihatmanto, A. S., \& Setiawan, A. (2019). The Potential of Gamification in Developing Pre-Service Physics Teachers' Critical and Creative Thinking Skills. Omega: Jurnal Fisika Dan Pendidikan Fisika, 5(1), 167-171. https://doi.org/10.31758/OMEGAJPHYSPHYSEDUC.V5I1.7.

Saprudin, S., Liliasari, L., Setiawan, A., \& Prihatmanto, A. (2020). Optical Gamification (OG); Serial Versus Random Model to Improve Pre-Service Physics Teachers' Concept Mastery. International Journal of Emerging $\begin{array}{llll}\text { Technologies in } & \text { Learning }\end{array}$ https://doi.org/https://doi.org/10.3991/ijet.v15i09.11779.

Sismulyasih, N. (2015). Peningkatan Keterampilan Menulis Manuskrip Jurnal Ilmiah Menggunakan Strategi Synergetic Teaching Pada Mahasiswa Pgsd Unnes. Primary: Jurnal Pendidikan Guru Sekolah Dasar, 4(1), 64-70. https://doi.org/http://dx.doi.org/10.33578/jpfkip.v4i1.2724.

Soegondo, S. P. S., \& Arifin, L. S. (2020). Service-Learning Dalam Pendidikan Arsitektur: Momen Kritis Dalam $\begin{array}{llll}\text { Suatu Refleksi. ATRIUM: Jurnal } & \text { Ersitektur, }\end{array}$ https://doi.org/https://doi.org/10.21460/atrium.v6i2.118.

Spencer, J. A. (2021). Integrating Service Learning into the RN to BSN Curriculum with the Application of QSEN $\begin{array}{llll}\text { Competencies. Journal of Professional } & \end{array}$ https://doi.org/https://doi.org/10.1016/j.profnurs.2021.08.007.

Suryandari, Sajidan, Rahardjo, Prasetyo, \& Fatimah. (2018). Project-Based Science Learning And Pre-Service Teachers' Science Literacy Skill And Creative Thinking. Cakrawala Pendidikan, 37(3). https://journal.uny.ac.id/index.php/cp/article/view/17229/pdf.

Syamsudduha, S., \& Tekeng, N. Y. (2017). Penerapan Service Learning Dalam Pembelajaran Matakuliah Pedagogik Pada Kurikulum Pendidikan Calon Guru. Jurnal Ilmu Tarbiyah Dan Pendidikan, 20(1), 1-17. https://doi.org/https://doi.org/10.24252/lp.2017v20n1a1.

Szanto, B. (2020). Reading and Writing Comprehension in the Mother Tongue in the Romanian National Assessment - Objectives, Tests, Results. Technium Social Science Journal, 9. https://doi.org/https://doi.org/10.47577/tssj.v9i1.933.

Warsihna, J. (2016). Meningkatkan Literasi Membaca Dan Menulis Dengan Teknologi Informasi Dan Komunikasi (TIK). Kwangsan, 4(2), 67-80. https://doi.org/https://doi.org/10.31800/jtp.kw.v4n2.p67--80.

Widayanti, Sutama, \& Wisudariani. (2019). Pengaruh Penerapan Model Pembelajaran Kooperatif Tipe Problem Posing Terhadap Hasil Belajar Menulis Cerita Fabel Pada Siswa Kelas VII SMP Negeri 2 Sawan Tahun Pelajaran 2018/2019. Jurnal Pendidikan Bahasa Dan Sastra Indonesia Undiksha, 9(1). https://doi.org/http://dx.doi.org/10.23887/jjpbs.v9i1.20268.

Widiarti, P. W. (2017). Konsep Diri (Self Concept) Dan Komunikasi Interpersonal Dalam Pendampingan Pada Siswa Smp Se Kota Yogyakarta. Informasi, 47(1), 135. https://doi.org/10.21831/informasi.v47i1.15035.

Windrawati, W., Solehun, \& Gafur, H. (2020). Analisis Faktor Penghambat Belajar Membaca Permulaan pada Siswa Kelas 1 SD Inpres 141 Matalamagi Kota Sorong. Jurnal Papeda, 2(1), 10-16. https://doi.org/https://doi.org/10.36232/jurnalpendidikandasar.v2i1.405.

Yasin, J. H. M., No, L., Gowa, K., Selatan, S., Ilmu, F., \& Iain, K. (2019). Higher Order Thinking Skills Assessment Based on Environmental Problem (HOTS-AEP): Mendesain Evaluasi Pembelajaran Abad 21 Ilmi. Jurnal Biotek, 7(1), 48-57.

Yulianingsih, W., Suhanadji, S., Nugroho, R., \& Mustakim, M. (2020). Keterlibatan Orangtua dalam Pendampingan Belajar Anak selama Masa Pandemi Covid-19. Jurnal Obsesi : Jurnal Pendidikan Anak Usia Dini, 5(2), 
1138-1150. https://doi.org/10.31004/obsesi.v5i2.740.

Yunita, Y., Fitri, F., \& Zulfahita, Z. (2017). Peningkatan Keterampilan Membaca Ekstensif Menggunakan Model Pembelajaran Reciprocal Teaching pada Siswa Kelas VIII D MTs Negeri Singkawang Tahun Ajaran 2016/2017. JP-BSI Uurnal Pendidikan Bahasa Dan Sastra Indonesia), 2(1), 12-17. https://doi.org/https://dx.doi.org/10.26737/jp-bsi.v2i1.231.

Yusnidar. (2014). Penerapan Metode Gallery Walk Untuk Meningkatkan Kemampuan Menulis Teks Analytical Exposition Bahasa Inggris Siswa Kelas Xi Ipa-1 Man Model Banda Aceh. Getsempena English Education Journal, 1(2). https://doi.org/https://doi.org/10.46244/geej.v1i2.676. 